\title{
AVALIAÇÃO DA APRENDIZAGEM E INCLUSÃO ESCOLAR: UM PROCESSO DE EXCLUSÃO OU UM ATO DE AMOR
}

\author{
EVALUACIÓN DEL APRENDIZAJE E INCLUSIÓN ESCOLAR: UN \\ PROCESO DE EXCLUSIÓN O UN ACTO DE AMOR
}

\section{EVALUATION OF LEARNING AND SCHOOL INCLUSION: A PROCESS OF EXCLUSION OR AN ACT OF LOVE}

\author{
Maria das Graças de Almeida BAPTISTA ${ }^{1}$ \\ Tânia Rodrigues PALHANO ${ }^{2}$ \\ Aline dos Santos PEREIRA ${ }^{3}$
}

RESUMO: Muito se tem escrito e falado sobre a inclusão escolar de alunos com necessidades educacionais especiais na rede regular de ensino. Entretanto, apenas a matrícula em si não é suficiente para incluir se não há condições efetivas de aprendizagem e avaliação, de forma que as diferenças sejam respeitadas e trabalhadas. O presente trabalho tem como objetivo estudar e analisar as diversas formas de avaliação do ponto de vista teórico e como elas podem contribuir com o sucesso da inclusão escolar. Apresentaremos o percurso histórico sobre os tipos de avaliação, uma breve reflexão sobre a inclusão e o papel do professor nesse processo e apontaremos o papel da avaliação na efetivação da inclusão escolar. Partindo dos princípios de que a educação é a base para o desenvolvimento do cidadão, e de que a inclusão escolar é um direito, e amparando-se nos pressupostos da concepção histórico-crítica, destacamos a contribuição da avaliação nesse processo. Contudo, se as necessidades dos discentes não são atendidas e a avaliação aponta as limitações e não as possibilidades, o processo de inclusão não poderá, de fato, se efetivar. As discussões aqui expostas apontam que, gradativa e interativamente, a inclusão está se efetivando, embora haja, ainda, um longo caminho a percorrer.

PALAVRAS-CHAVE: Avaliação da aprendizagem. Necessidades educacionais especiais. Inclusão escolar.

\footnotetext{
${ }^{1}$ Universidade Federal da Paraíba (UFPB), João Pessoa - PB - Brasil. Professora vinculada ao Departamento de Fundamentação da Educação - Centro de Educação da Universidade Federal da Paraíba e credenciada junto ao Programa de Pós-Graduação em Educação/PPGE/UFPB na Linha de Pesquisa em Processos de Ensino-Aprendizagem. Líder do Grupo de Estudos e Pesquisa em Filosofia e Psicologia da Educação ÁGORA/UFPB. E-mail: mgabaptista2@yahoo.com.br.

${ }^{2}$ Universidade Federal da Paraíba (UFPB), João Pessoa - PB - Brasil. Professora vinculada ao Departamento de Fundamentação da Educação - Centro de Educação da Universidade Federal da Paraíba e credenciada junto ao Programa de Pós-Graduação em Educação/PPGE/UFPB na Linha de Pesquisa em Processos de Ensino-Aprendizagem. Líder do Grupo de Estudos e Pesquisa em Filosofia e Psicologia da Educação ÁGORA/UFPB. E-mail: taniarpalhano@gmail.com.

${ }^{3}$ Rede Municipal de Ensino de João Pessoa - PB - Brasil. Especialista em Educação em Direitos Humanos pela UFPB e em Psicopedagogia Institucional pelo Centro Integrado de Tecnologia e Pesquisa (CINTEP), Pedagoga pela Universidade Federal da Paraíba e Graduanda em Psicologia pela Faculdade Internacional da Paraíba (FPB). E-mail: aline.educ@outlook.com.
} 
RESUMEN: Mucho se ha escrito y hablado respecto a la inclusión escolar de alumnos con necesidades educacionales especiales, en la red regular de enseñanza. Sin embargo, sólo la matrícula no es suficiente para incluir se no hay condiciones efectivas de aprendizaje y evaluación, de forma que las diferenciaciones sean respetadas y trabajadas. Este trabajo tiene por objetivo estudiar y analizar las diversas formas de evaluación del punto de vista teórico y como ella puede contribuir con el éxito de la inclusión escolar. Presentamos el trayecto histórico sobre los tipos de evaluación, una reflexión rápida sobre la inclusión y el papel del profesor en ese proceso y apuntamos el papel de la evaluación en la efectivación de la inclusión escolar. Partiendo de los principios de que la educación es la base para el desarrollo del ciudadano y que la inclusión escolar es un derecho , y amparándose en los presupuestos de la concepción histórico crítica, ponemos de relieve la contribución de la evaluación en dicho proceso. Contudo, se as necessidades dos discentes não são atendidas e a evaluación apunta las limitaciones y no las posibilidades, el proceso de inclusión no podrá, de hecho, efectivarse. Las discusiones aquí expuestas apuntan que gradativa e interactivamente la inclusión está efetivándose, aunque haya, aún, un largo camino a recorrer.

PALABRAS CLAVE: Evaluación del aprendizaje. Necesidades educacionales especiales. Inclusión escolar.

ABSTRACT: Much has been written and spoken about the school inclusion of students with special educational needs in the regular school network. However, registration alone is not sufficient to include if there are no effective learning and assessment conditions, so that the differences are respected and worked out. The present study aims to study and analyze the different forms of evaluation from a theoretical point of view and how it can contribute to the success of school inclusion. We will present the historical course on the types of evaluation, a brief reflection on the inclusion and the role of the teacher in this process and we point out the role of evaluation in the effectiveness of school inclusion. Based on the principles that education is the basis for the development of the citizen and that school inclusion is a right, and based on the assumptions of the historical-critical conception, we highlight the contribution of evaluation in this process. However, if the student needs are not met and the evaluation points out the limitations, not the possibilities, the inclusion process can not actually take place. The discussions here show that, gradually and interactively, inclusion is taking place, although there is still a long way to go.

KEYWORDS: Learning evaluation. Special educational needs. School inclusion.

\section{Introdução}

A educação é um direito básico assegurado pela Constituição Federal (CF) de 1988 e pela Lei de Diretrizes e Bases (LDB) de 1996, que também traz considerações 
importantes acerca da inserção de alunos com necessidades educacionais especiais na escolar regular, reafirmando a igualdade de oportunidade para todos.

$\mathrm{O}$ acesso, e a permanência, dos alunos com necessidades educacionais especiais perpassam por adaptações na metodologia de ensino e nas avaliações e por investimentos na capacitação dos profissionais da educação, para lidar com o diferente, evitando uma mera integração na sala de aula. Cabe à escola - enquanto instituição social - e ao Estado, promover e garantir meios de acesso e de permanência, ofertando assistência adequada às diferentes necessidades educacionais e formação adequada para que os professores adaptem suas práticas pedagógicas à demanda exigida.

A avaliação escolar enquanto prática tradicional reduz a avaliação ao ato de classificar e selecionar os que se adaptam ao sistema normativo, desconsiderando e excluindo aqueles que não acompanham o ritmo de ensino-aprendizagem.

Segundo Luckesi (2011, p. 29), “o educando não vem para a escola ser submetido à um processo seletivo, mas sim para aprender e, para tanto, necessita do investimento da escola e de seus educadores, tendo em vista efetivamente aprender". A partir dessa premissa, a avaliação é essencial na prática pedagógica inclusiva, subsidiando a aprendizagem do aluno e seu desenvolvimento, como ele encara o processo de aprendizagem, quais atividades ele pode realizar sozinho e quais ele precisa da mediação do professor.

A partir dessas considerações, o objetivo do presente trabalho é estudar e analisar as diversas formas de avaliação do ponto de vista teórico e como ela pode contribuir com o sucesso da inclusão escolar. Com esse objetivo, discorremos sobre o processo de inclusão de alunos e alunas com necessidades especiais na rede regular de ensino, levantando os seguintes questionamentos: Como tem se dado a avaliação no processo de inclusão na escola regular? Como adequar a avaliação escolar como mais um recurso no processo de inclusão?

O trabalho apresenta um percurso histórico sobre os tipos de avaliação e como é sua prática no cotidiano da escola, uma breve reflexão sobre o processo de inclusão, a legislação brasileira acerca da inclusão no Brasil e o papel do professor nesse processo. A metodologia aplicada ao trabalho consiste em uma revisão de literatura, utilizando livros, revistas e artigos científicos relacionados ao tema, amparando-se nos pressupostos da concepção histórico-crítica. 


\section{A avaliação e seu percurso histórico}

A avaliação é um conceito que nomeia os objetivos estabelecidos em sala de aula na construção do conhecimento e o resultado final, verificando quais objetivos foram alcançados e quais as dificuldades foram encontradas para possíveis intervenções pedagógicas.

Segundo Luckesi (2011, p. 27), “a avaliação da aprendizagem é um termo recente, já os exames escolares antecedem a avaliação e são usados há séculos, porém da forma que atualmente é aplicada nas escolas, vem sendo utilizado há cerca de quinhentos anos.”.

Didática Magna de Jan Amós Komensky, Comenius (1592-1670), para Luckesi (2011, p. 191), era um "guia” para o ensino em geral e o modo do professor proceder nas correções das atividades em sala já demonstrava o que estava por vir nos exames. Comenius, (2001, p.306), no princípio "Como examinar as lições ditadas e escritas", orienta: "manda ler o escrito a um ou a dois ou, se necessário, a vários, com voz clara e distinta, e notando também expressamente os sinais de pontuação; os outros, olhando cada um o seu caderno, corrigem", cabendo ao professor "de vez em quando examinar ele próprio os cadernos de um ou dois alunos, ao acaso; e, se for encontrado algum negligente, seja castigado".

Uma avaliação usada como fonte de castigo moral, segundo Luckesi (2011, p. 190), pode ser descrita como "uma forma de castigar um pouco mais sutil que as anteriores, que existiu no passado e ainda existe, é a prática pela qual o professor cria um clima de medo tensão e ansiedade entre os alunos: faz-se uma pergunta a um deles passando-a para um segundo", procedendo igualmente em relação ao terceiro, ao quarto e provocando tensão nos alunos à medida que "cada um espera ser o próximo".

A esse respeito, no princípio "Como se estimular para os estudos", Comenius (2001, p. 451) orienta que a utilização de "outros meios e melhores que as pancadas: às vezes, com uma palavra mais áspera e com uma repreensão dada em público; outras vezes, elogiando os outros", ou "suscitando o riso", ou ainda "estabelecer-se desafios ou sabatinas semanais, ou ao menos mensais, para ver a quem cabe o primeiro lugar ou a honra de um elogio", sendo "absolutamente necessário que o professor assista ao desafio e o dirija com seriedade e sem artifícios, censure e repreenda os mais negligentes e elogie publicamente os mais aplicados". 
A Ratio Studiorum "Plano de estudos" de 1594, um manual com 467 regras, orientava todos que faziam parte do processo de ensino, regulamentava como o professor devia organizar sua aula, a forma de aplicar e corrigir os exames e de premiar os alunos que se destacavam nas provas. Algumas das regras estimulavam a individualidade e a concorrência entre os colegas de classe.

Em 1930, Ralph Tyler preocupado com o alto índice de reprovação nas escolas, como aponta Luckesi, (2011, p. 28), propõe um novo fazer pedagógico, de forma que aumentasse a aprendizagem dos educandos através do cuidado com o ensino e da reorientação. "(1) ensinar alguma coisa, (2) diagnosticar sua consecução, (3) caso a aprendizagem fosse satisfatória, seguir em frente, (4) caso fosse insatisfatória, proceder a reorientação, tendo em vista obter o resultado satisfatório".

Através destas breves indicações, fica evidente que após 87 anos da proposta de Tyler ainda não conseguimos pôr em prática a obviedade da reorientação pedagógica proposta por ele. Os professores se preocupam em seguir à risca um currículo de forma a preparar os alunos para provas que, presumem, irão aferir a capacidade de acumular fórmulas e macetes e "treiná-los" para a competição do mercado capitalista. A preocupação com a aprendizagem, com o significado do conhecimento e sua ressignificação fica, na maior parte do tempo, em segundo ou terceiro plano.

Somente em 1970, o Brasil começa a trabalhar com o termo avaliação da aprendizagem e é com a Lei de Diretrizes e Bases de 1996 que o conceito foi incorporado à legislação educacional atual, embora na prática ainda haja um caminho a percorrer no sentido de compreender o seu lugar e o seu papel no processo de ensino e de aprendizagem em sala de aula.

\section{Tipos de avaliação}

Com tantas peculiaridades e divisões, a avaliação avança à medida que novas pesquisas são desenvolvidas. Na prática da sala de aula, são diversas as vertentes, as circunstâncias, as concepções que devem ser consideradas na hora de planejar a avaliação. Partindo do pressuposto que estamos trabalhando a avaliação na perspectiva de um processo de ensino-aprendizagem satisfatório, iremos nos ater às concepções de avaliação de Luckesi (2011) e Perrenout (1999) cujas abordagens partem da ideia de que a avaliação 
pensada apenas para selecionar os melhores, mantém a ordem social de uma sociedade hierarquizada.

Em seu livro Avaliação da aprendizagem escolar: estudos e proposições, Luckesi cita e reflete sobre três tipos de avaliação. Primeiro, a avaliação classificatória é eficiente na manutenção do modelo de sociedade atual, ela é disciplinadora quando o professor a usa para "domesticar" os alunos, julgadora quando separa os alunos bons dos maus (há até quem separe esses alunos por classe) e estigmatizadora quando os alunos que não alcançaram uma média de aprovação são excluídos e vistos pela comunidade escolar como alunos "burros", com déficit de aprendizagem ou nível cognitivo baixo. Qualquer que seja o adjetivo utilizado, o aluno é desqualificado e isso prejudica o seu rendimento em sala, fazendo-o sentir-se inferior aos demais.

Luckesi (2011, p. 84-85), aponta que "a curva estatística, dita normal, permanecerá normal. Assim sendo, a sociedade definida permanece como está, pois a distribuição social das pessoas não pode ser alterada com a prática pedagógica, mesmo dentro dos seus limites". E, assim, "a gana conservadora da sociedade permite que faça da avaliação um instrumento nas mãos do professor autoritário para hostilizar os alunos, exigindo-lhe condutas das mais variadas, até mesmo as plenamente irrelevantes" e, por ser "autoridade, assume a postura de poder exigir a conduta que quiser, quaisquer que sejam".

O segundo tipo de avaliação é a avaliação diagnóstica que, segundo o autor, tem o propósito de sondar o nível de conhecimento do aluno, a fim de que o professor trace estratégias, investindo no processo (resultado da aprendizagem) e não no produto (nota), de forma que o aluno tenha um desempenho satisfatório. Logo, se "investimos no processo, o resultado da aprendizagem, manifestado pelo estudante vai ser qualificado em satisfatório ou em insatisfatório": "se for satisfatório está bem; porém, se for insatisfatório, há que se intervir para que a aprendizagem se manifeste satisfatória” (LUCKESI, 2011, p.63).

Por fim, a avaliação participativa. Feita a avaliação diagnóstica, a avaliação participativa assume o caráter de abordar os erros e acertos de forma amorosa e de descobrir como foram construídas as respostas para chegar a tal resultado. Luckesi (2011, p. 118) afirma que, nesse tipo de avaliação, os resultados "deverão ser utilizados para diagnosticar a situação do aluno, tendo em vista o cumprimento das funções de autocompreensão".

Por sua vez, Perrenoud (1999, p. 36), em seu livro Avaliação da excelência à regulação das aprendizagens: entre duas lógicas, dá ênfase à dois tipos de avaliação: a 
tradicional e a formativa. A avaliação tradicional engendra e amplia as desigualdades e exclusões sociais, prejudicando a aprendizagem ao tratar todos como iguais, não considerando a heterogeneidade que é inerente em uma sala de aula. Segundo o autor, "as hierarquias de excelência escolar teriam menos peso, durante a escolaridade e depois dela, se os principais interessados duvidassem da realidade de certas desigualdades que elas pretendem 'refletir', nem mais, nem menos". E afirma que, "graças a essas crenças fundadas ou não -, é possível transformar os julgamentos de excelência em julgamentos de êxito ou fracasso e depois tomar, com base nisso, decisões graves, que afetam a progressão no curso, a orientação ou certificação.

A avaliação formativa, que não se separa da didática, não se preocupa em classificar ou selecionar, mas em intervir de forma diferenciada, se atendo a causa das dificuldades do educando. Esse tipo de avaliação "assume todo seu sentido no âmbito de uma estratégia pedagógica de luta contra o fracasso e as desigualdades, que está longe de ser sempre executada com coerência e continuidade". Assim, enquanto "instrumento de uma pedagogia diferenciada", a avaliação formativa "não dá as costas à certificação, visa sobretudo a criação das condições da certificação do maior número de alunos. Afastar as escalas irreversíveis, introduzir as habilitações o mais tarde possível" (PERRENOUD, 1999, p. 164).

Apesar da nomenclatura diferente, os autores concordam que a avaliação pode ser antagônica ao processo de ensino aprendizagem ao se constituir indiferente ao diferente, mas também pode ser um instrumento para a democratização do ensino.

\section{Educação Inclusiva no Brasil}

Todo brasileiro, independente de cor, sexo, gênero e posição socioeconômica, são iguais perante a Constituição e tem como direito inalienável, uma educação pública e de qualidade, garantido pelo Estado. Contudo, nem sempre foi assim. De acordo com a cartilha Projeto Escola Viva, distribuída pela Secretaria de Educação Especial em 2005, o Estado não tinha a responsabilidade de oferecer educação para todos, o que excluía pobres e escravos.

De acordo com essa cartilha, a Constituição brasileira (1824) "foi o primeiro documento oficial a manifestar o interesse do País pela educação de todos os cidadãos, ao estabelecer a gratuidade da instrução primária. Entretanto, ela não explicitou de quem seria 
a responsabilidade pelo sistema e pelo processo educacional", eximindo "o poder público desse compromisso". Logo, o texto "que aparentemente se comprometia com os brasileiros, na verdade se referia tão somente a uma pequena minoria, representada pela elite sociopolítica no País" (BRASIL, 2005, p. 5-6).

A partir dessa conjuntura, pode-se afirmar que as pessoas que necessitavam de atendimento educacional especializado estavam excluídas, inclusive da escola. Em 1961, mudanças visando a inserção de alunos com necessidades especiais na escola regular começaram a surgir, considerando que havia capacidades cognitivas que poderiam e deveriam ser potencializadas se devidamente estimuladas, apesar das dificuldades motoras, cognitivas ou mentais que eles pudessem apresentar: 'de maneira geral, os dispositivos legais se referem à educação desse segmento populacional como um direito a ser usufruído, quando possível, no sistema regular de ensino" (BRASIL, 2005, p. 6). Enfim, até então, a supressão dos direitos por acreditar na incapacidade das pessoas com deficiência só contribuiu para a marginalização, e quando não, para as atitudes paternalistas que "protegiam" os deficientes da sociedade ao segregá-los.

Na década de 90, a Declaração de Salamanca apresenta princípios concernentes aos direitos das pessoas com necessidades educacionais especiais. O Brasil, ao concordar com os ideais discutidos em Jomtien, em 1990, e com a Declaração de Salamanca, em 1994, avança discutindo possibilidades e estratégias para a inclusão dessas pessoas no sistema regular de ensino. Assim como, ao se comprometer com o processo de inclusão de alunos com necessidades educacionais especiais, o Estado, a escola, os profissionais que nela trabalham e os familiares passam a ter responsabilidades distintas, porém com o mesmo objetivo, auxiliar o educando na inclusão na sociedade e na escola.

Entretanto, apesar de alguns avanços, ainda se confunde o processo de integração com o processo de inclusão. O processo de integração prepara a pessoa com deficiência para se adequar a sociedade, enquanto que o processo de inclusão busca adaptar a sociedade ao cidadão com deficiência. A esse respeito, Briant e Oliver (2012, p. 142) salientam que, o direito à "participação de crianças com deficiência na escola" depende, "entre outros aspectos, da articulação entre profissionais, famílias e sociedade", além da “destinação de recursos humanos e materiais e formação de profisssionais habilitados para o enfrentamento dos diferentes desafios trazidos pela prática cotidiana do ensino", entre outros aspectos. 
À família cabe a responsabilidade de matricular seu filho na escola de ensino regular e buscar apoio nas instituições públicas capacitadas para dar suporte ao educando e à família. Ao Estado compete proporcionar recursos financeiros e humanos, através da capacitação dos profissionais envolvidos no atendimento ao educando com necessidades especiais, e promover programas de conscientização à população quanto a importância do acolhimento para o bem-estar das pessoas com algum tipo de deficiência e da responsabilidade social em construir uma sociedade inclusiva.

A escola, por sua vez, deve ocupar-se em conhecer seus educandos, identificar suas necessidades especiais e desenvolver práticas pedagógicas que atendam suas especificidades e possibilitem o compartilhamento e a construção do conhecimento. $\mathrm{O}$ atendimento educacional especializado, conforme sinaliza Carneiro (2015, p. 122),

\footnotetext{
se operacionaliza através das seguintes conformidades organizacionais do sistema de ensino: i) matrícula dos alunos preferencialmente nas escolas regulares e nas classes comuns; ii) professores devidamente capacitados e especializados; iii) flexibilizações e adaptações circulares com foco o significado prático e instrumental dos conteúdos essenciais; iv) metodologias de ensino e recursos didáticos diferenciados; v) processos de avaliação adequados ao desenvolvimento dos alunos que apresentam necessidades educacionais especiais: vi) projeto pedagógico permeável à diferença e à diversidade; vii) serviços de apoio pedagógicos especializado para complementação ou suplementação curricular.
}

Qualquer criança que durante o processo de ensino-aprendizagem, devido as suas limitações físicas ou cognitivas, apresentar a necessidade de apoio diferenciado para um aprendizado satisfatório, pode ser considerado um aluno com necessidade educacional especial e precisa da adaptação da escola às suas necessidades.

\section{Educação inclusiva e legislação}

O Brasil possui um vasto repertório de leis, portarias, decretos e resoluções que direcionam e apontam as diretrizes para o processo de inclusão. Pode-se citar como principais documentos reguladores do processo de inclusão a Constituição, por ser o documento que rege o país, e a LDB, por se tratar da lei que dá sustentação legislativa às ações do Estado enquanto responsável por uma educação pública de qualidade e apoiador das ações pedagógica. 
A Constituição Federal de 1988, como principal documento norteador do Estado, em seu Artigo 206, afirma que deve haver a igualdade de condições para o acesso e permanência na escola. No Artigo 208, fica clara a responsabilidade do Estado ao mencionar que "é dever do Estado o atendimento educacional especializado aos portadores de deficiência, preferencialmente na rede regular de ensino".

A LDB, enquanto conjunto de normas que norteia a educação no Brasil, traz uma série de orientações, fundamentos, direitos dos educandos e deveres do Estado e da escola para que o atendimento seja de fato inclusivo. No artigo 58 do Capítulo V, conforme aponta Carneiro (2015, p. 608), a lei esclarece que por educação especial entende-se "a modalidade de educação escolar, oferecida preferencialmente na rede regular de ensino, para educandos portadores de necessidades especiais" e, nos parágrafos desse mesmo artigo destaca que: "§ $1^{\circ}$ Haverá, quando necessário, serviços de apoio especializado, na escola regular, para atender as peculiaridades da clientela de educação especial"; "§2 $\mathrm{O}$ atendimento educacional será feito em classes, escolas ou serviços especializados, sempre que, em função das condições específicas dos alunos, não for possível a sua integração nas classes comuns do ensino regular"; “ $\$ 3^{\circ}$ A oferta da educação especial, dever constitucional do Estado, tem início na faixa etária de zero a seis anos, durante a educação infantil”.

Entretanto, apesar dessa vasta legislação em prol do efetivo processo de inclusão escolar e social, fruto de muitos enfrentamentos, certamente esforços ainda serão empreendidos no sentido da conscientização de uma sociedade que aprendeu a excluir ainda no processo de colonização e traz consigo essa herança discriminatória.

\section{O papel do professor no processo de inclusão na rede regular de ensino}

Historicamente, os relatos acerca da inclusão demonstram que, aqueles que apresentavam alguma deficiência sofriam abandono, isolamento ou eram sacrificados. Hoje, apesar dos esclarecimentos acerca do tema, ainda ocorre abandono, isolamento e discriminação.

Mundialmente, somos uma sociedade bastante heterogênea, tanto em relação à cultura, à raça, à crença, às características físicas, ao sexo, gênero, e às limitações cognitivas. A sociedade, ao pretender igualar pessoas, negando suas diferenças, apenas demonstra o quanto é discriminatória. 
Na escola também não é diferente. Trabalha-se com um único método de ensino, um único currículo e uma única avaliação, na vã tentativa de igualar o desenvolvimento cognitivo de uma turma heterogênea.

A escola, enquanto instituição social que mais publiciza o processo de inclusão, tem em sua maioria, estruturas físicas que não possibilitam o acesso para alunos com deficiências físicas e visuais (a exemplo das rampas), falta recursos audiovisuais, ledor, tecnologia assistiva e tantos outros recursos que possibilitariam uma melhor recepção à esses educandos, assim como falta professor especializado para trabalhar com os surdos e cegos, tornando praticamente impossível a acessibilidade e a permanência do educando na escola.

Percebe-se que a falta de recursos físicos, pedagógicos e humanos na rede regular de ensino é responsável pela relutância em matricular alunos com necessidades educacionais especiais, fazendo-o tão somente por que é obrigatório, mas sem esforço de fato no sentido de incluí-lo. Segundo Carneiro (2015, p. 125), "os sistemas e as escolas devem criar condições para que o professor da classe comum possa explorar as potencialidades de todos os estudantes, adotando uma pedagogia dialógica, interativa, interdisciplinar". Assim como, "na interface, o professor do atendimento educacional especializado (AEE) deve identificar habilidades e necessidades dos estudantes, organizar e orientar sobre os serviços e recursos pedagógicos e de acessibilidade para a participação e aprendizagem dos estudantes".

Para superar a distância entre o discurso e a prática na escola, cabe a cada professor, individualmente, tornar-se responsável por procurar formação e fazer leituras que o auxiliem a trabalhar com esses educandos. Adaptar o currículo, as atividades e a avaliação, através de um planejamento que respeite os limites cognitivos e físicos dos educandos, trabalhando os conteúdos necessários, é umas das muitas formas de tentar superar as dificuldades encontradas na sala de aula.

Entretanto, embora seja o professor o profissional que tem uma relação mais próxima com os educandos, convivendo diariamente com as suas dificuldades, se não houver uma prática interdisciplinar e um atendimento multidisciplinar de profissionais para que haja uma evolução na sua deficiência, o processo de inclusão não se efetiva e o professor fica sobrecarregado.

Briant e Oliver $(2012$, p. 142, 147) defendem que "a composição de uma equipe multidisciplinar é fundamental para apoiar e construir novas possibilidades de ação por 
parte dos diferentes agentes e para a efetivação e fortalecimento de uma nova dinâmica que valorize cada sujeito e sua diversidade". Ou seja, "contar com uma rede de apoio possibilita que o trabalho fique mais estruturado, o aluno com deficiência deixa de ser visto como um problema e o professor sente-se mais livre para exercer sua criatividade e encontrar respostas positivas".

Além disso, faz-se inerente ao fazer pedagógico a reflexão e a avaliação dessa prática e nunca esquecer a finalidade da educação escolar, que é ensinar à todos a construir e reconstruir conhecimento.

A prática da avaliação, enquanto parte do processo de inclusão na escola, não naturaliza o fracasso e a reprovação, pelo contrário sua finalidade é oferecer subsídios ao professor para que todos os educandos tenham êxito independente de suas limitações. Para o sucesso da avaliação, faz-se mister trabalhar situações concretas da realidade do educando, a partir de sua inserção na sociedade e na sala de aula, e não de forma hipotética, idealizada, sobre tal ou qual conteúdo deve ser trabalhado e cobrado em determinado ano, a despeito de que os alunos acompanhem esse ou aquele ritmo de aprendizagem.

A avaliação vigente, segundo Luckesi (2011, p. 69), é um processo excludente não apenas em relação aos alunos deficientes, mas aos socialmente desfavorecidos, ou seja, a avaliação tem sido um instrumento a favor da sociedade elitista e hierarquizada, uma vez que o seu emprego tem impedido aos já marginalizados o acesso à educação.

Quanto mais ignorância e inconsciência, sinaliza o autor, "melhor para os segmentos dominantes da sociedade. Para ele torna-se necessário controlar o montante de pessoas educadas atendendo as necessidades do modo de produção capitalista. Esse montante, se ultrapassar os limites de controle, poderá gerar desequilíbrio e processos de transformação". Ou seja, "a sociedade burguesa procura por diversos mecanismos limitar o acesso e a permanência das crianças e jovens no processo de escolaridade. Em função disso, o ensino não poderá ser democratizado do ponto de vista da permanência escolar". Portanto, "tanto a questão da permanência quanto a questão da terminalidade têm implicações sérias e graves contra a democratização do ensino", uma vez que, "os poucos que ingressam na escola aí não permanecem por diversos fatores e os que permanecem por algum tempo adquirem uma terminalidade que pouco significa para a elevação do seu patamar cultural (LUCKESI, 2011, p. 98-99). 
Uma avaliação que não se preocupa com o aprendizado, a repetência e a desmotivação do educando em se sentir incapaz de realizar as atividades propostas é antidemocrática, é um desserviço à educação emancipatória. Tornar a avaliação algo difícil, não estimula os educandos a progredir nos estudos, e aplicar uma avaliação sem levar em consideração as limitações físicas, cognitivas e sociais, é apenas mais um instrumento de exclusão. É nesse contexto, sinaliza Luckesi (2011, p. 153), que "emergem as questões tão faladas de pré-requisitos. Um educando que não possui os pré-requisitos para uma aprendizagem não poderá efetivá-la”.

Logo, no processo de inclusão, a avaliação não deve ser trabalhada com acento na quantificação, mas enquanto qualificação do desenvolvimento do conhecimento do educando, para isso, a flexibilização da avaliação é fator importante, uma vez que interfere diretamente no êxito avaliativo dos alunos com necessidades educacionais especiais. A abstração do processo de aprendizagem deve ser avaliada de forma contínua, para que se possa qualificar o conhecimento do educando e verificar sua aptidão, de forma que o professor possa avançar nos conteúdos curriculares.

Assim, a prática classificatória da avaliação, conforme aponta Luckesi (2011, p. 112), é “antidemocrática, uma vez que não encaminha uma tomada de decisão para o avanço, para o crescimento. Essa prática classificatória da avaliação confirma a nossa hipótese de que a atual prática de avaliação do aluno é uma prática antidemocrática no que se refere ao ensino". Essa prática "se torna mais grave quando entendemos que um aluno pode ser aprovado ou reprovado por um contrabando entre qualidade e quantidade".

Apostar em avaliações alternativas, não desassociando-as da didática e da realidade do educando, é fator determinante na construção das possibilidades de descobrir a melhor forma de qualificar o desenvolvimento dos educandos. Perceber as dificuldades, reinventar a prática pedagógica e a avaliação, promover a compreensão e o crescimento cognitivo do educando e a sua promoção às series subseqüentes, aumenta o interesse e o índice de permanência do educando com necessidade educacional especial na escola, rompendo assim com a sociedade elitista e contribuindo de fato para um ensino inclusivo e democrático.

\section{Avaliação versus hierarquia social}


$\mathrm{Na}$ sociedade, a crise de valores e a hierarquia social reflete-se na escola, que, aparentemente, tem se conformado com as desigualdades, subordinações, exclusões, competições, alto índice de repetência e o sucesso escolar de uma minoria, uma vez que a educação participa das mudanças sócio-históricas da sociedade. Nessa relação, a sociedade transforma a educação e a educação transforma a sociedade, ou seja, a educação possui uma dimensão social no seu fazer educativo, já que ela é resultado de um dado momento histórico, a tempo que, ao se modificar, transforma a sociedade. Tendo em vista essa relação dinâmica, a sociedade hierarquizada e, verticalizada, promove uma escola com características similares à sua, para a manutenção da ordem social.

Luckesi (2011, p. 204), ressalta que mudar a avaliação é algo difícil, visto que a sociedade não é amorosa e a prática exercida é a compatível com os anseios da sociedade elitista.

A aprovação de uns poucos e a reprovação de muitos outros na escola, por sua vez, alimenta a hierarquia social. Segundo Perrenoud, $(1999$, p. $9 ; 13 ; 26)$ "a avaliação inflama as paixões e estigmatiza a ignorância de alguns para melhor celebrar a excelência de outros". Para aqueles que se encaixam nos padrões de normalidade e desenvolvimento cognitivo, a avaliação é uma experiência recompensadora, para outros, a avaliação é uma experiência vexatória e traumática. Para àqueles que não se encaixam nos padrões de normalidade e não celebram o sucesso da aprovação, "são relegados às habilitações préprofissionais; por outro, os que avançam no curso se orientam para os estudos aprofundados".

Para o autor, "a pesquisa em educação jamais ignorou o peso das normas de excelência escolar na determinação do êxito e do fracasso escolar"; entretanto, "durante muito tempo considerou-se sua existência e seu conteúdo como evidências triviais, e a avaliação como uma simples medida das desigualdades de domínio da cultura escolar”.

Assim, a ideia que transpassa a prática avaliativa corrobora com a prática da exclusão, da hierarquia e da verticalização social e escolar.

\section{Avaliação versus um ato de amor}

Para avaliar o educando, é preciso reconhecer a diversidade existente na sala de aula, pela sua inserção em uma sala heterogênea, em que nem todos têm a mesma relação com a leitura e escrita e os números. Logo, torna-se mister acolher o educando, verificar o 
nível de conhecimento e dar condições para que haja inclusão, desenvolvimento cognitivo e familiaridade com o conhecimento adquirido.

Contudo, conforme expõe Morin (2013, p. 73), "não se trata de descongelar as palavras do ensino, mas de reaquecê-las. Como Platão disse há muito tempo: para ensinar é necessário o "Eros", o que "não se resume apenas ao desejo de conhecer e transmitir, ou ao mero prazer de ensinar, comunicar ou dar: é também amor por aquilo que se diz e do que pensa ser verdadeiro. É o que introduz a profissão pedagógica, a verdadeira missão do educador".

A avaliação torna-se, assim, um ato de amor, onde não há espaço para julgamentos de certo ou errado, mas de assistir na dificuldade do educando. Segundo Luckesi (2011, p. 204-206), a definição de avaliação enquanto ato amoroso tem algumas características, tais como: o acolhimento, a integração e a inclusão, sintetizando o ato de avaliar com amor. Esse ato é "um ato que acolhe atos, ações, alegrias e dores como eles são; acolhe para permitir que cada coisa seja o que é, neste momento. Por acolher a situação como ela é, o ato amoroso tem a característica de não julgar". Dessa forma, a "avaliação da aprendizagem escolar como um ato amoroso, na medida em que a avaliação tem por objetivo diagnosticar e incluir o educando, pelos mais variados meios, no curso da aprendizagem satisfatória que integre todas as suas experiências de vida".

Avaliar com amor é criar meios de como incluir o educando no processo de aprendizagem, direcionando e auxiliando. Para auxiliar no desenvolvimento do processo de aprendizagem, Luckesi (2011, p. 210-211) cita três cuidados na avaliação em sala: primeiro, "na correção das avaliações para não expor a intimidade do aluno, mas reorientando com carinho"; segundo, a avaliação deve: abordar "os assuntos vistos em sala para que o aluno não tenha a sensação de ter perdido tempo estudando um assunto que não foi abordado em sala"; "não exigir habilidades e competências que não foram trabalhadas"; e "utilizar uma linguagem compatível com o nível de conhecimento do educando para não causar confusão na interpretação e por fim, que o instrumento de avaliação demonstre a importância dos conteúdos estudados". Por fim, "não borrar a avaliação do aluno com cores fortes e na devolutiva, auxiliar o educando nas dificuldades apresentadas".

Esses cuidados parecem óbvios, mas no imediatismo do cotidiano escolar, esquecemos, desconhecemos, que nosso compromisso é possibilitar meios que proporcionem aos educandos o envolvimento nas atividades em sala de aula, de forma a 
possibilitar a apropriação do conhecimento historicamente acumulado e o ressignifique socialmente.

A avaliação não deve ser um ato seletivo, mas um instrumento manejado com amor, cujo objetivo é promover o crescimento do educando, ajudando o professor no diagnóstico e em futuras tomadas de decisões visando o desenvolvimento cognitivo do aluno.

\section{Considerações finais}

A avaliação pode ser um instrumento importante para motivar e incluir o educando enquanto sujeito, assim como pode oferecer subsídios para o professor ao apontar onde se encontram as dificuldades do aluno. Ao conhecer a origem das dificuldades do educando, cria-se possibilidades, no fazer pedagógico, de incluir os alunos que necessitam de um atendimento educacional especializado e de identificar os alunos que, por diversos fatores, têm dificuldade em realizar determinadas tarefas. Trabalhar a construção do aprendizado a partir do erro do educando não significa enfatizar o erro ou enaltecê-lo, mas entender o porquê do erro.

Pode-se afirmar que a escola e a sociedade muito têm a aprender sobre o acolhimento dos educandos e das pessoas que necessitam de um atendimento educacional especial. Entretanto, apesar das pesquisas e dos debates acerca do tema, percebe-se que as políticas educacionais que tratam do processo de inclusão precisam caminhar junto com a formação dos professores, na defesa de um currículo flexível.

Reconhece-se a dificuldade da escola e de seus profissionais de propor alternativas que efetivem o processo de inclusão, uma vez que a escola e seus profissionais estão inseridos em uma sociedade elitista, meritocrática, classista, onde uma maioria deve se submeter aos ditames de uma minoria que detém as forças produtivas, e cuja base está fundamenta na exploração dos excluídos e no estigma sobre aqueles que diferem do padrão normativo de normalidade.

Uma escola que valoriza a quantificação, a seleção, o ranking escolar e a necessidade de certificação, está simplesmente cumprindo o papel que a sociedade burguesa lhe designou. Entretanto, enquanto espaço de contradição, essa mesma escola tem rompido com esses estigmas e tem tentado amorosamente avaliar e incluir o educando que 
apresenta alguma deficiência, assim como o aluno socialmente excluído, compreendendo suas dificuldades e construindo alternativas que contribuam com a transformação social.

\section{REFERÊNCIAS}

BRASIL. Constituição da República Federativa do Brasil. Brasília: Supremo Tribunal Federal, Secretaria de Documentação, 2017. 514 p.

BRASIL. Ministério da Educação, Secretaria de Educação Especial. Projeto Escola Viva: Garantindo o acesso e permanência de todos os alunos na escola - Alunos com necessidades educacionais especiais. Brasília: MEC/SEESP, 2005, vol. 5.20 p.

BRIANT, Maria Emília Pires.; OLIVER, Fátima Corrêa. Inclusão de crianças com deficiência na escola regular numa região do município de São Paulo: conhecendo estratégias e ações. Revista Brasileira de Educação Especial, Marília, v. 18, n. 1, p. 141154, jan./mar. 2012.

CARNEIRO, Moaci Alves. LDB fácil: leitura crítico-compreensiva, artigo a artigo. Petropólis, RJ: Vozes, 2015. 845 p.

COMENIUS, Iohannis Amos. Didactica Magna. Versão para eBook: eBooksBrasil.com. In. Como examinar as lições ditadas e escritas. Disponível em: <https://social.stoa.usp.br/articles/0016/1300/Didatica_Magna_COMENIUS.pdf >. Acesso em: 01 jul. 2017.

COMENIUS, Iohannis Amos. Didactica Magna. Versão para eBook: eBooksBrasil.com. In: Como se estimular para os estudos. Disponível em: $<$ https://social.stoa.usp.br/articles/0016/1300/Didatica_Magna_COMENIUS.pdf>. Acesso em: 01 jul. 2017.

DECLARAÇÃO DE SALAMANCA. Sobre princípios, políticas e práticas na área das necessidades educativas especiais. Espanha, 1994. 17 p.

LUCKESI, Cipriano Carlos. Avaliação da aprendizagem escolar: estudos e proposições. São Paulo: Cortez, 2011. 272 p.

MORIN, Edgar. Educação e complexidade: os sete saberes e outros ensaios. São Paulo: Cortez, 2013. 109 p.

PERRENOUD, Philippe. Avaliação: da excelência à regulação das aprendizagens: entre duas lógicas. Porto Alegre: Artes médicas, 1999. 183 p. 


\section{Como referenciar este artigo}

BAPTISTA, Maria das Graças de Almeida.; PALHANO, Tânia Rodrigues.; PEREIRA, Aline dos Santos. Avaliação da aprendizagem e inclusão escolar: um processo de exclusão ou um ato de amor. Revista on line de Política e Gestão Educacional, Araraquara, v.21, n. esp.2, p. 1335-1352, nov. 2017. Disponível em: <http://dx.doi.org/10.22633/rpge.v21.n.esp2.2017.10174>. ISSN: 1519-9029.

Submetido em: 23/07/2017

Aprovado em: 20/08/2017 